\title{
Controllable Biogenic Synthesis of Intracellular Silver/Silver Chloride Nanoparticles by Meyerozyma guilliermondii KX008616
} \author{
Gamal A. El-Shaboury ${ }^{1}$ \\ ${ }^{1}$ Department of Biology, Faculty of Science, King Khalid University, Abha 61421, Saudi Arabia \\ ${ }^{2}$ Department of Botany and Microbiology, Faculty of Science, Assiut University, Assiut 71515, Egypt \\ ${ }^{3}$ Department of Physics, Faculty of Science, King Khalid University, Abha 61421, Saudi Arabia \\ ${ }^{4}$ Department of Physics, Faculty of Science, AlAzhar University, Assiut 71524, Egypt
}

Saad A.M. Alamri ${ }^{1}$, Mohamed Hashem ${ }^{1,2 *}$, Nivien A. Nafady ${ }^{2}$, Mahmoud A. Sayed ${ }^{3,4}$, Ali M. Alshehri ${ }^{1}$, and

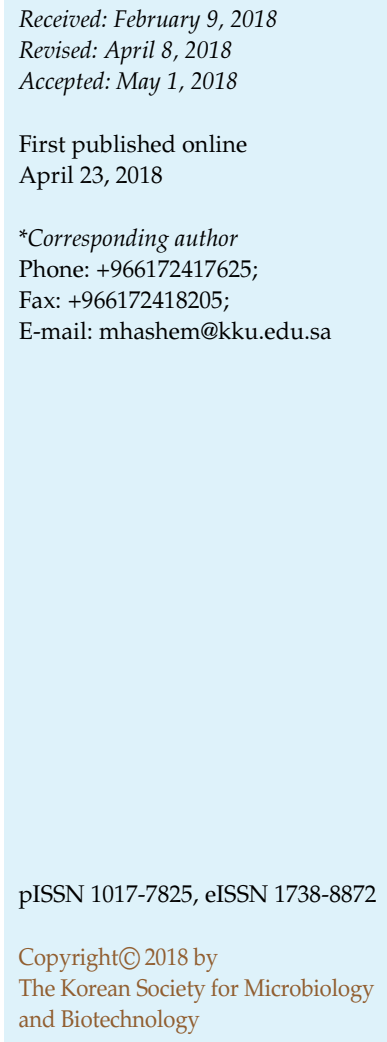

Intracellular synthesis of silver/silver chloride nanoparticles (Ag/AgCl-NPs) using Meyerozyma guilliermondii KX008616 is reported under aerobic and anaerobic conditions for the first time. The biogenic synthesis of Ag-NP types has been proposed as an easy and cost-effective alternative for various biomedical applications. The interaction of nanoparticles with ethanol production was mentioned. The purified biogenic Ag/AgCl-nanoparticles were characterized by different spectroscopic and microscopic approaches. The purified nanoparticles exhibited a surface plasmon resonance band at 419 and $415 \mathrm{~nm}$, confirming the formation of $\mathrm{Ag} / \mathrm{AgCl}-$ NPs under aerobic and anaerobic conditions, respectively. The planes of the cubic crystalline phase of the $\mathrm{Ag} / \mathrm{AgCl}-\mathrm{NPs}$ were confirmed by X-ray diffraction. Fourier-transform infrared spectra showed the interactions between the yeast cell constituents and silver ions to form the biogenic Ag/AgCl-NPs. The intracellular Ag/AgCl-NPs synthesized under aerobic condition were homogenous and spherical in shape, with an approximate particle size of $2.5-30 \mathrm{~nm}$ as denoted by the transmission electron microscopy (TEM). The reaction mixture was optimized by varying reaction parameters, including temperature and $\mathrm{pH}$. Analysis of ultrathin sections of yeast cells by TEM indicated that the biogenic nanoparticles were formed as clusters, known as nanoaggregates, in the cytoplasm or in the inner and outer regions of the cell wall. The study recommends using the biomass of yeast that is used in industrial or fermentation purposes to produce $\mathrm{Ag} / \mathrm{AgCl}-\mathrm{NPs}$ as associated by-products to maximize benefit and to reduce the production cost.

Keywords: Ag/AgCl-NPs, ethanol, fermentation, intracellular synthesis, Meyerozyma guilliermondii, X-ray, transmission electron microscope

\section{Introduction}

Nanotechnology is a multidisciplinary science that deals with very small particles ranging from 1 to $100 \mathrm{~nm}$ and has been utilized in many applications such as medicine, pharmacy, industry, and agriculture [1, 2]. Nanoparticles of some metals like $\mathrm{Au}, \mathrm{Ag}, \mathrm{Pt}$, and $\mathrm{Cu}$ have attracted more attention because of their biotechnological benefits [3, 4], owing to their unique chemical and physical properties that differ from the metallic particles $[5,6]$. Recently, metal nanoparticles have emerged as an alternative type of antibacterial agent against strains with high resistance to the classical antibiotics [7, 8], antiviral agents [9], anticancer cells and antitumor [10], antifungal [11], antiprotozoal [12], larvicidal [13], anthelmintic [14], and acaricidal [15] agents.

Nanoparticles can be produced either by physical or chemical methods [3]. However, biological production of such important nanoparticles by microorganisms represent a great achievement because it is economic and ecofriendly [16, 17]. Many microorganisms, especially fungi 
and bacteria, were approved for their ability to produce different nanoparticles of metals [18, 19]. Fungi were mentioned as excellent candidates for metal nanoparticle synthesis because they contain many enzymes that induce reduction of the metals [20-23].

Current research focuses on the production of nanoparticles by fungi and bacteria; however, production of nanoparticles by yeasts is still restricted to some species. Agnihotri et al. [24] revealed that yeast strains that were isolated from extreme environmental niches, such as marine, psychro, thermo, or acidic habitats, showed a high potential to synthesize metal nanoparticles. Apte et al. [25] reported that psychrotrophic marine ascomycetous yeast, Yarrowia lipolytica, synthesized silver nanoparticles. Mourato et al. [26] reported the successful manufacturing of silver nanoparticles by yeast isolated from an extreme acidic mine. Fernández et al. [27] approved the production of silver nanoparticles using the culture supernatants of Cryptococcus laurentii and Rhodotorula glutinis. They mentioned that these yeasts were chosen for their nitrate reductase activity. These findings support the hypothesis that stress conditions could induce different physiological pathways that lead to the synthesis of nanoparticles by such microorganisms. Despite the wealth of knowledge on bioproduction of silver nanoparticle types by yeasts, only one report has examined the ability of different yeast strains to biosynthesize silver nanoparticle types [28]. They provide the first evidence of yeast strains assisting in the synthesis of silver/silver chloride nanoparticles (Ag/AgCl-NPs).

Yeasts as a specific group of microorganisms were approved for their efficiency of bioaccumulation of heavy metals many years ago [29]. Moreover, we assume that ethanol production by yeasts during the fermentation process represents a kind of physiological stress, in which the vegetative growth nearly ceased, and the cell is turned into a biofactory for the production of ethanol. In addition, investigation of new species of yeasts to synthesize metal nanoparticle types could provide new nanoparticles with distinctive characteristics, such as specific shapes and sizes, that make them more applicable in different fields. From this point of view, we assume that inoculation of the fermentation medium with silver nitrate $\left(\mathrm{AgNO}_{3}\right)$ could have a good impact on nanoparticle type production by the fermentative yeasts. We identified yeast isolates that biosynthesized $\mathrm{Ag} / \mathrm{AgCl}-\mathrm{NPs}$ under both aerobic and anaerobic conditions. The purified silver nanoparticle types were characterized by a variety of spectroscopy techniques. In addition, we tested different $\mathrm{pH}$ values and reaction temperatures, and factors under aerobic and anaerobic conditions, to expand our information as to what extent these factors can affect the shape and size of biogenic nanoparticles. Furthermore, we tested the susceptibility of the yeast isolate to produce ethanol during the process of biogenic production of nanoparticles.

\section{Materials and Methods}

\section{Isolation and Identification of Yeast Strain}

The yeast strain used in this study was isolated from naturally fermented wasted rice. The wasted rice sample was obtained from a restaurant before disposal, and was ground using a laboratory blender to obtain the mash with a diameter of particles smaller than $3 \mathrm{~mm}$. Twenty-five grams of the ground sample was poured into a 250-ml Erlenmeyer flask and the volume was completed to $100 \mathrm{ml}$ with sterilized distilled water. The flask was sealed with a fitted cotton plug and incubated in a rotatory shaker $(150 \mathrm{rpm})$ at $25^{\circ} \mathrm{C}$ for 5 days until natural fermentation occurred and the odor of ethanol was evident. The desired volume $(50 \mu \mathrm{l})$ was spread on yeast extract-malt extract agar $(3 \mathrm{~g} / 1$ of yeast extract, $3 \mathrm{~g} / 1$ of malt-extract, $5 \mathrm{~g} / \mathrm{l}$ of peptone, and $10 \mathrm{~g} / \mathrm{l}$ of glucose, $\mathrm{pH}$ 6.0) and was allowed to grow for $48-72 \mathrm{~h}$ at $25^{\circ} \mathrm{C}$ [30]. The emerged yeast isolates were purified by streaking on the same agar medium at least twice to get a single colony and then they were kept in slants of the same medium at $4^{\circ} \mathrm{C}$ for further use. The purified yeast isolate was identified by sequencing of the D1/D2 domain of the $26 \mathrm{~S}$ rDNA region. The extraction of total yeast genomic DNA was performed according to the procedure described by Hesham et al. [31]. The D1/D2 domain of the 26S rDNA region was amplified using the primers NL1 (5'-GCATATCAATAAGCGGAGGAAAAG$\left.3^{\prime}\right)$ and NL4 (5'-GGTCCGTGTTTCAAGACGG-3') as mentioned by Kurtzman and Robnett [32]. The amplified D1/D2 fragments were purified and sequenced at Macrogen Company (Korea). The obtained sequence of 26S rDNA was aligned with known 26S rDNA sequences in the GenBank database and the percentage homology score was generated to identify the yeast.

\section{Ag/AgCl-NP Synthesis under Aerobic and Anaerobic Conditions}

Yeast extract-malt extract broth medium (YMB) was used as a growth medium either for preparing the yeast inoculum or the production of $\mathrm{Ag} / \mathrm{AgCl}-\mathrm{NPs}$. The inoculum of the yeast isolate was prepared freshly by growing for $48 \mathrm{~h}$ in a rotatory shaker incubator $(200 \mathrm{rpm})$ at $25^{\circ} \mathrm{C}$. Five milliliters of the freshly prepared inoculum at a cell density of $10^{8}$ cell $/ \mathrm{ml}$ was injected into a $250-\mathrm{ml}$ conical flask containing $100 \mathrm{ml}$ of the $\mathrm{YMB}$ medium at $25^{\circ} \mathrm{C}$ in a rotatory shaker incubator (200 rpm) for $12 \mathrm{~h}$. Then, the medium was supplemented with $5 \mathrm{ml}$ of $\mathrm{AgNO}_{3}(100 \mathrm{mM})$. In the case of aerobic incubation, the conical flasks were plugged with fitted sterilized cotton plugs; however, another set of conical flasks were plugged with fitted plastic screw caps to create an anaerobic atmosphere for the fermentation process. The control flasks were not supplemented with $\mathrm{AgNO}_{3}$ solution. In both experiments, the 
growing incubation temperature was adjusted to $25^{\circ} \mathrm{C}$ and the $\mathrm{pH}$ was 7 . The incubated flasks were observed for color change, which was the sign for $\mathrm{Ag} / \mathrm{AgCl}-\mathrm{NPs}$ formation. The time at which the color of the medium changed was recorded.

\section{Purification of the Intracellular Synthesized Ag/AgCl-NPs}

After formation of the $\mathrm{Ag} / \mathrm{AgCl}-\mathrm{NPs}$ in the culture, which was indicated by a shift of the color of the medium from pale yellow to dark brown, a known volume of the culture was centrifugated at $5,000 \mathrm{rpm}$ for $10 \mathrm{~min}$ to precipitate the yeast cell containing the intracellular Ag/AgCl-NPs. The collected yeast cells were washed three times with addition of distilled water and recentrifuged at the same conditions to discard any residue of the medium. The washed yeast cells were dispersed in a volume of distilled water and were sonicated for $10 \mathrm{~min}$ (Qsonica Sonicator, Q700) to liberate the nanoparticles into the solution. The intracellular Ag/ $\mathrm{AgCl}-\mathrm{NPs}$ were purified by centrifuging them at $12,000 \mathrm{rpm}$ for $15 \mathrm{~min}$. The supernatant was discarded, and the pellets were dispersed with distilled water and recentrifuged. This process was repeated three times to remove the free entities and unbound biological molecules from the $\mathrm{Ag} / \mathrm{AgCl}-\mathrm{NPs}$. The obtained nanoparticles were dried at $50-60^{\circ} \mathrm{C}$ and stored in a brown-glass container for further characterization.

\section{Intracellular $\mathrm{Ag} / \mathrm{AgCl}-\mathrm{NP}$ Characterization}

The biogenic silver nanoparticle types were characterized by ultraviolet-visible (UV-VIS) spectroscopy, transmission electron microscopy (TEM), x-ray diffraction (XRD), and Fourier-transform infrared (FT-IR) spectroscopy. The concentration of purified Ag/ $\mathrm{AgCl}-\mathrm{NPs}$ in the solution was measured with atomic absorption spectroscopy (Model 210 VGP; Buck Scientific, USA) equipped with a silver hollow cathode lamp and air-acetylene flame.

Ultraviolet-visible spectroscopy. A strong absorption of electromagnetic waves is exhibited by metal nanoparticles in the visible range owing to surface plasmon resonance (SPR). The spectral analysis was done by using a Jasco V-570 UV/VIS/NIR spectrophotometer in the range $300-800 \mathrm{~nm}$. The stability of stored Ag/AgCl-NPs biologically synthesized by yeast cells was also determined by UV-Vis spectral analysis.

$X$-ray diffraction. The formation of the crystalline biosynthesized silver nanoparticle types by yeast cells was checked by XRD analysis using a Shimadzu X-ray $(\mathrm{Cu} k \alpha)$ Diffractometer XRD$6000(\lambda=1.5406 \AA)$ operated at $30 \mathrm{kV}$ and 25 with a step of $0.02^{\circ}$ in the $2 \theta$ range of $20^{\circ}-80^{\circ}$.

Transmission electron microscope analysis. The size and surface morphology of the synthesized $\mathrm{Ag} / \mathrm{AgCl}-\mathrm{NPs}$ were studied using JEOL TEM (Model 100 CXII) at the Electron Microscope Unit, Assiut University (Egypt). A drop of the purified nanoparticle dispersion $(100 \mu \mathrm{g} / \mathrm{ml})$ was placed on a carbon-coated copper grid and dried at room temperature.

Fourier-transform infrared analysis. FT-IR analysis was performed to determine the possible functional groups in the yeast cells responsible for bioreduction of silver ions and formation of biogenic intracellular Ag/AgCl-NPs. A very small quantity of the sample was mixed with $\mathrm{KBr}$ powder to make a pellet, which was subjected to FT-IR analysis in the Thermo Scientific Nicolet 6700 FT-IR spectroscopy device. For attenuation of noise ratio, 32 scans were taken at the range of $450-4,000 \mathrm{~cm}^{-1}$ and the resolution was kept at $8 \mathrm{~cm}^{-1}$.

\section{Effect of Incubation Temperatures on Ag/AgCl-NP Formation}

The effect of incubation temperatures $\left(25^{\circ} \mathrm{C}, 30^{\circ} \mathrm{C}\right.$, and $\left.40^{\circ} \mathrm{C}\right)$ on the biogenic $\mathrm{Ag} / \mathrm{AgCl}-\mathrm{NP}$ production was studied by inoculating the YMB medium with $5 \mathrm{ml}$ of the yeast inoculum under aerobic and anaerobic conditions, as mentioned above. The formation of $\mathrm{Ag} / \mathrm{AgCl}-\mathrm{NPs}$ by yeast cells were determined by UV-Vis spectral analysis.

\section{Effect of $\mathrm{pH}$ on $\mathrm{Ag} / \mathrm{AgCl}-\mathrm{NP}$ formation}

The effect of initial pH values (3.0, 4.0, 5.5, 6.0, and 7.0) on the biogenic $\mathrm{Ag} / \mathrm{AgCl}-\mathrm{NP}$ production was carried out by inoculating the YMB medium (of different $\mathrm{pHs}$ ) with $5 \mathrm{ml}$ of the yeast inoculum under aerobic and anaerobic conditions, as mentioned above. The $\mathrm{pH}$ was adjusted with $1 \mathrm{~N} \mathrm{HCl}$ or $0.1 \mathrm{~N} \mathrm{NaOH}$. The formation and stability of $\mathrm{Ag} / \mathrm{AgCl}-\mathrm{NPs}$ by yeast cells was determined by UV-Vis spectral analysis.

\section{Ultrathin Sections of Yeast Cells}

Yeast cell membrane morphology and localization of the Ag/ AgCl-NPs were studied using the transmission electron microscope. Yeast cells were harvested from log-phase cultures (grown under aerobic and anaerobic conditions at different $\mathrm{pH}$ values). The yeast cells were fixed in $2 \%$ glutaraldehyde, post-fixed in osmium tetroxide, dehydrated in an ascending acetone series, and embedded in Spurr's resin. Ultrathin sections $(60-90 \mathrm{~nm})$ were cut with an ultramicrotome (Reichart Ultracuts). Staining was done by a double-staining technique using uranyl acetate and lead citrate. Ultrathin sections were examined and photographed with the TEM (JEOL,100 CXII) operating at $200 \mathrm{kV}$.

\section{Bioethanol Production by Meyerozyma guilliermondii KX008616} in the Presence of Different Concentrations of Silver Nitrate

The inoculum of the yeast isolate was prepared by transferring one loopful of 48-h culture grown on a slant of YMPA into a 250-ml Erlenmeyer flask containing $50 \mathrm{ml}$ of sterilized YMP broth. Production of ethanol was conducted at $25^{\circ} \mathrm{C}$ in $250-\mathrm{ml}$ glass bottles containing $100 \mathrm{ml}$ of sterilized YMP broth, and the $\mathrm{pH}$ was adjusted to 5 . The fermentation medium was amended with different concentrations of $\mathrm{AgNO}_{3}(0,2,4,6$, and $8 \mathrm{mM})$. Then, $5 \mathrm{ml}$ of the yeast inoculum $\left(10^{8} \mathrm{cell} / \mathrm{ml}\right)$ was added to the fermentation medium. The bottles were plugged with fitted plastic screw caps and were incubated in a rotatory shaking incubator $(200 \mathrm{rpm})$ at $25^{\circ} \mathrm{C}$ for $60 \mathrm{~h}$ under anaerobic condition. Three bottles were used for each concertation of $\mathrm{AgNO}_{3}$, and $5 \mathrm{ml}$ was taken each $12 \mathrm{~h}$ for ethanol estimation. Concentrations of ethanol in the samples were estimated enzymatically using 
estimation kits (K620-100) according to the procedures provided by BioVision (USA) [33].

\section{Results and Discussion}

A purified yeast isolate was identified using phylogenetic analysis of $18 \mathrm{~S}$ rRNA gene sequences. The partial $18 \mathrm{~S}$ rRNA gene sequence of approximately 614 base pairs of Meyerozyma guilliermondii KX008616 has a sequence with 100\% similarity to Meyerozyma guilliermondii MGYN-1 (KJ641911) that is available in the GenBank database.

Laboratory experiments proved the ability of $M$. guilliermondii KX008616 to produce Ag/AgCl-NPs under aerobic and anaerobic conditions in concentrations of 113.576 and $55.237 \mathrm{ppm}$, respectively. The color of the inoculated medium changed from yellow to brown owing to the SPR phenomenon, indicative of the reduction of silver ions and formation of bio-nanoparticles. The reduction of $\mathrm{AgNO}_{3}$ could be conducted by constituents of the yeast cells. Examining the yeast cells using the light microscope showed that those growing either aerobically or anaerobically in growth medium amended with $\mathrm{AgNO}_{3}$ changed into pale brown color compared with the normal clear cells in the control medium (Figs. 1A-1C). This indicates their ability to reduce the silver ions into Ag-NPs or AgCl-NPs. Interestingly, the aggregation of the cells that appeared during fermentation (Fig. 1C) proved the viability of the cells. This finding indicates the ability of the yeast cell to carry out both fermentation and bioreduction of $\mathrm{AgNO}_{3}$ at the same time. Production of intra- and/or extracellular nanoparticles of metals by some yeasts like Candida glabrata, Schizosaccharomyces pombe, Pichia jadinii, and Yarrowia lipolytica was previously mentioned [34]. The findings support our results and confirms the assumption that the type of nanoparticle production (intracellular, extracellular, or on the cell surface) depends on the organism itself. The synthesis of silver nanoparticles by yeasts was reported as either intra- or extracellular depending upon the species being taken into use [35]. These authors proved the production of silver nanoparticles by Saccharomyces cerevisiae after $36 \mathrm{~h}$ of incubation with nutrients and subsequent dilution in $30 \%$ ethanol. The reduction of the metal by the yeast cells was suggested through two mechanisms. The first mechanism is the participation of a sulfate or nitrate reductase system that is capable of working in the presence of ATP and $\mathrm{NADH}$ or anthraquinone [36]. The other mechanism is via activation of a specific polypeptide chain (PC) involving a repeating sequence of general formula ( $\gamma$-Glu-Cys) $n$ Gly with $n$ values commonly ranging from 2 to 6 . They might bind to the cationic species, immediately forming a cationicPC complex that is transported into the vacuole, where it is degraded and the nanoparticles are formed [37, 38]. The formation of silver nanoparticles on the cell surface could be due to the electrostatic interaction between the $\mathrm{Ag}^{+}$and the negatively charged carboxylate groups present either on specific enzymes, proteins like cysteine, or even polypeptides present on the cell wall $[39,40]$.

The UV-Vis absorbance is a good indicator for confirming the formation of $\mathrm{Ag} / \mathrm{AgCl}-\mathrm{NPs}$ by M. guilliermondii. As seen from Fig. 2, the purified nanoparticles exhibited an SPR band at $419 \mathrm{~nm}$, confirming the formation of $\mathrm{Ag} / \mathrm{AgCl}-$ NPs under aerobic condition. The stability of the biogenic silver nanoparticle types was checked after a considerable period of time (up to 64 days), and it was found that the absorbance spectra of the Ag/AgCl-NPs showed the same plasmonic absorption in the visible region with only a slight shift from 419 to $425 \mathrm{~nm}$ [41, 42]. As the particles destabilize with time, the original peak ( $1^{\text {st }}$ day) will decrease in intensity, which may be due to the depletion of stable nanoparticles, and the peak will be broader, which may be due to the formation of aggregates [43-45].

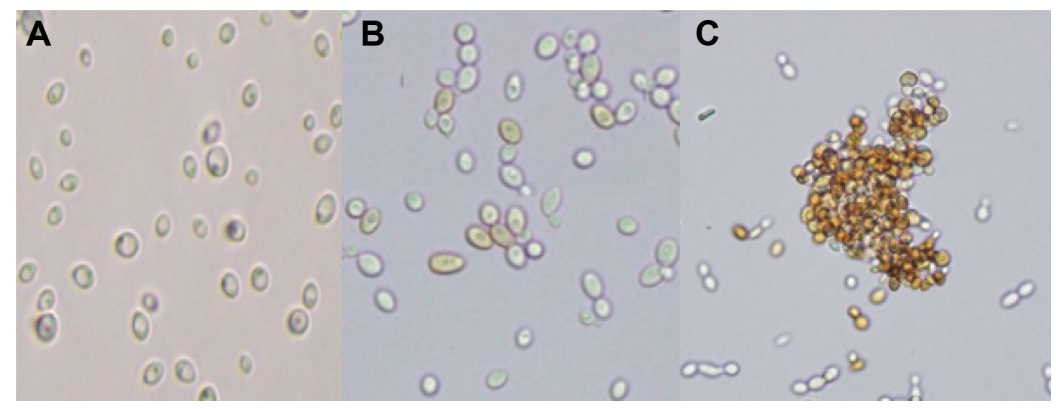

Fig. 1. Light photographs of yeast cells in control medium (A), in medium supplemented with silver nitrate under aerobic condition (B), and in medium supplemented with silver nitrate under anaerobic condition (C).

The color shift from pale to dark brown indicates the intracellular production of $\mathrm{Ag} / \mathrm{AgCl}$-nanoparticles. 


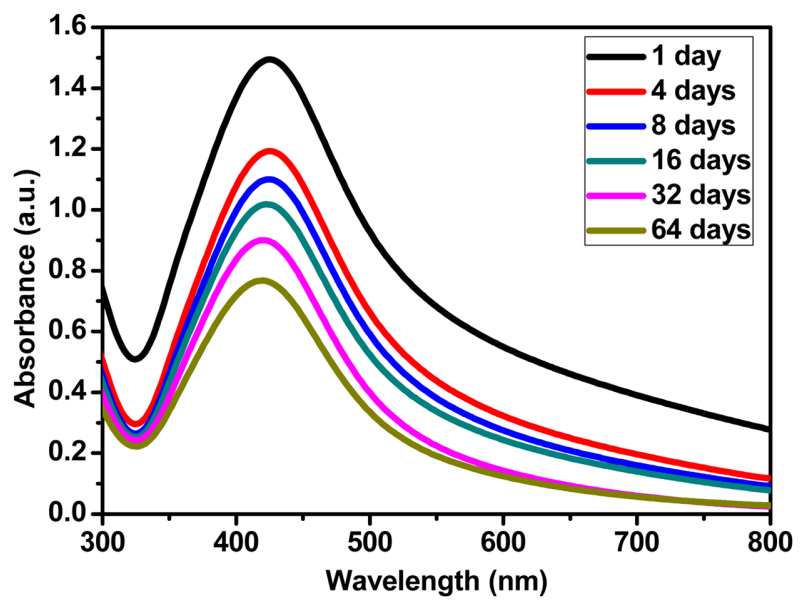

Fig. 2. UV-visible absorbance spectra of biogenic Ag/AgClNPs synthesized intracellularly by Meyerozyma guilliermondii KX008616 under aerobic condition at different storage times, $\mathrm{pH} 7$, and $25^{\circ} \mathrm{C}$.

The formation of the crystalline intracellular $\mathrm{Ag} / \mathrm{AgCl}-$ NPs biosynthesized by M. guilliermondii KX008616 under aerobic and anaerobic conditions was checked by XRD (Figs. 3A and 3B). Under aerobic conditions, the XRD chart exposed the presence of four characteristic peaks at $2 \theta$ values of $38^{\circ}, 44^{\circ}, 64^{\circ}$, and $78^{\circ}$ that were attributed to the (111), (200), (220), and (311) planes of the cubic crystalline phase of the silver nanoparticles, which coexisted with others, and eight peaks at $2 \theta$ values of $27^{\circ}, 32^{\circ}, 46^{\circ}, 55^{\circ}, 57^{\circ}$, $67^{\circ}, 74^{\circ}$, and $76^{\circ}$ indexed as (111), (200), (220), (311), (222), (400), (331), and (420) were attributed to planes of the cubic crystalline phase of silver chloride [28, 46]. However, under anaerobic conditions, most peaks did not clearly appear. This may be due to the changing of the phase to spherical. This interpretation of the $\mathrm{Ag} / \mathrm{AgCl}-\mathrm{NP}$ diffraction profiles is consistent with the standards set by the Joint Committee on Powder Diffraction Standards (JCPDS Card No. 04-0783, to silver nanoparticles, and JCPDS No. 311238, to silver chloride nanoparticles). As seen in Figs. 3A and $3 \mathrm{~B}$, there were no other peaks, in the sense that the high purity of $\mathrm{Ag} / \mathrm{AgCl}-\mathrm{NPs}$ and the highly crystalline structure was revealed from the strong and narrow diffraction peaks [47].

The size and shape of the intracellular Ag/AgCl-NPs were determined by TEM (Fig. 4). Measurements of biosynthesized nanoparticles diameters (600 Ag/ AgClNPs) showed that the average diameter was $16.3 \pm 9.01 \mathrm{~nm}$ under aerobic condition and $34.4 \pm 23.39 \mathrm{~nm}$ under anaerobic condition. Most of the intracellular nanoparticles
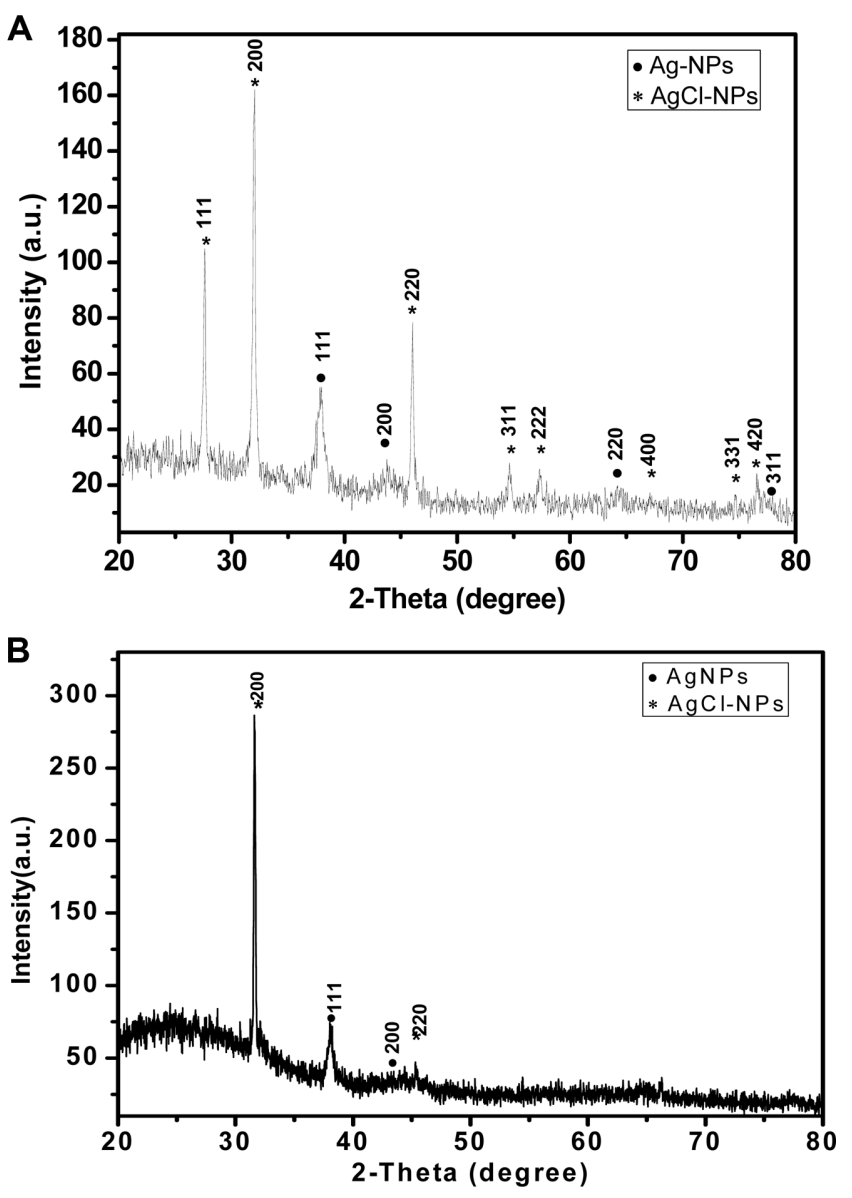

Fig. 3. X-ray diffraction patterns of the biogenic $\mathrm{Ag} / \mathrm{AgCl}-$ nanoparticles synthesized by Meyerozyma guilliermondii KX008616 under (A) aerobic and (B) anaerobic conditions.

synthesized under aerobic condition were homogeneous and spherical in shape (Fig. 4A). It was clear that the biogenic nanoparticles formed under the aerobic condition was in the range of $2.5-30 \mathrm{~nm}$ and displayed polydispersity. Moreover, there was diversity in the shapes of the biogenic nanoparticles under the anaerobic condition, of which spherical and polyhedral nanoparticles were found (Fig. 4C).

FT-IR spectral analysis were carried out to identify the possible functional groups in yeast cells responsible for the reduction of silver ions to silver and silver chloride nanoparticles as well as to identify the capping and efficient stabilization agents in the biosynthesized Ag/ AgCl-NPs. The FT-IR spectra for both aerobic and anaerobic conditions are demonstrated in Figs. 5A and 5B, respectively. It was recorded that the infrared spectra are similar, but they showed an observed difference of peak intensity at 3,420 and $1,077 \mathrm{~cm}^{-1}$. The broad absorption band that centered 
A

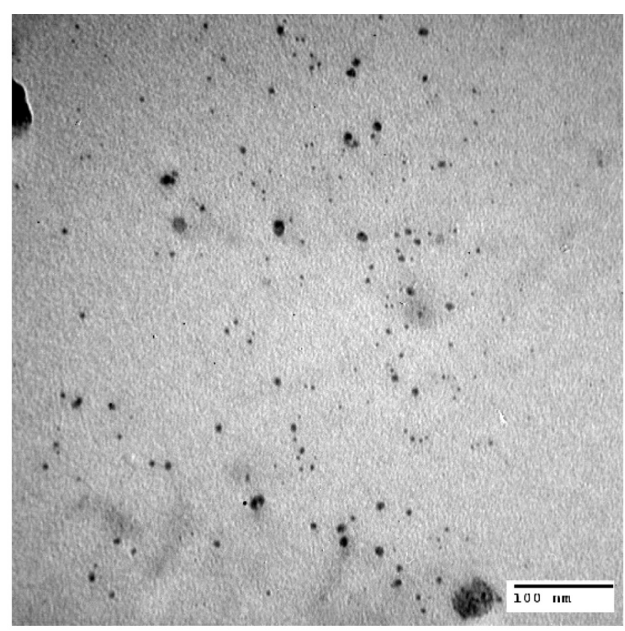

C

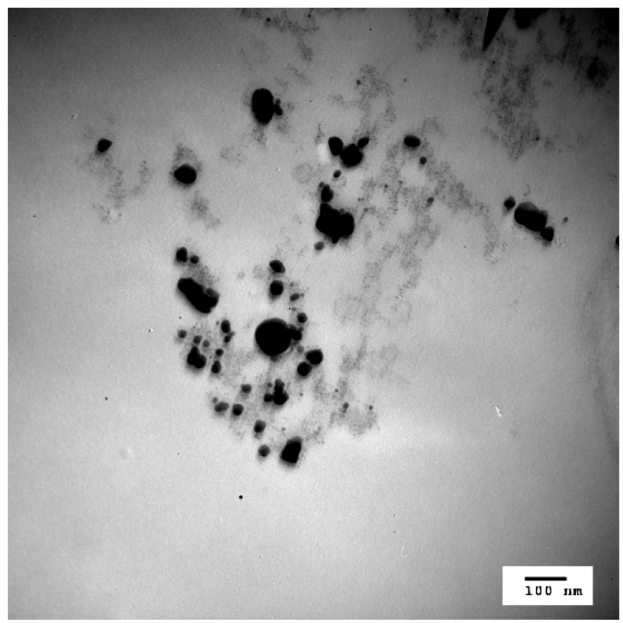

B

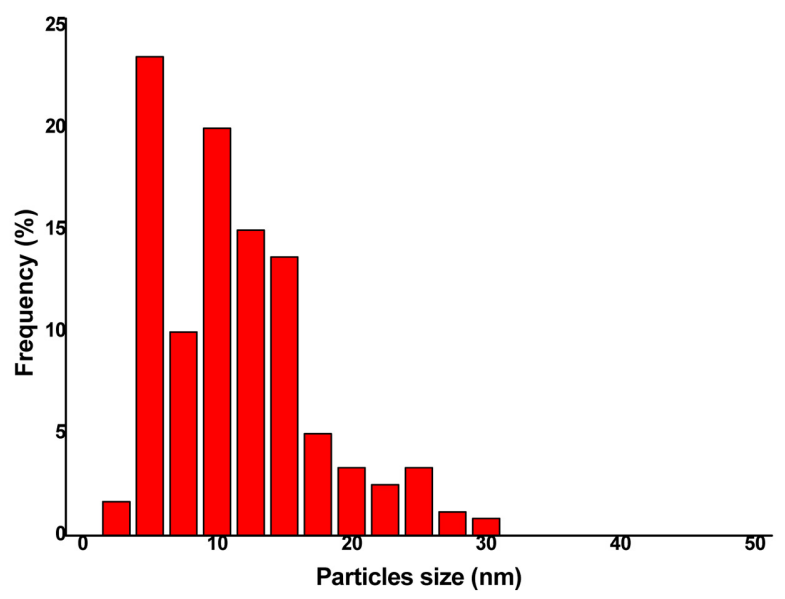

D

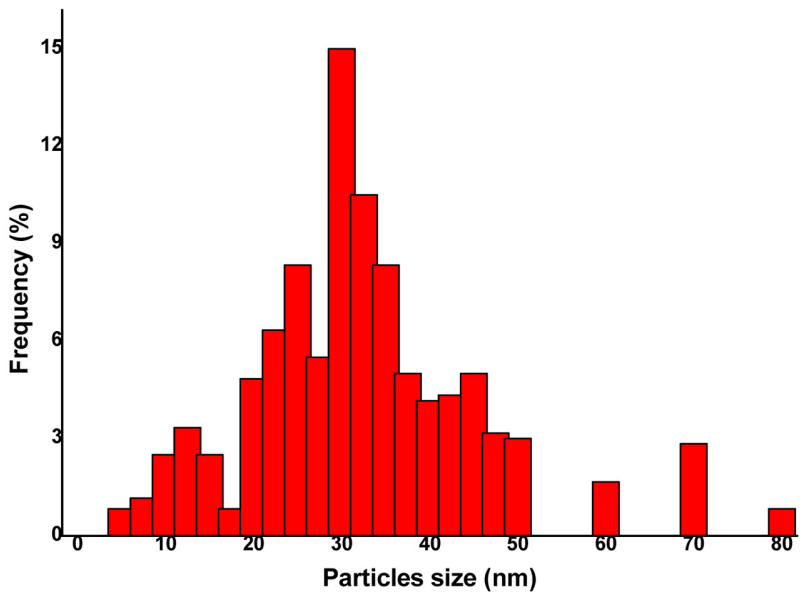

Fig. 4. Representative transmission electron micrographs of biogenic $\mathrm{Ag} / \mathrm{AgCl}$-nanoparticles synthesized intracellularly using Meyerozyma guilliermondii KX008616 under (A) aerobic and (C) anaerobic conditions, and (B, D) histograms of particle size distributions.

about 3,420 and $3,412 \mathrm{~cm}^{-1}$ for the aerobic and anaerobic conditions, respectively, are characteristic of the $\mathrm{O}-\mathrm{H}$ or $\mathrm{N}-\mathrm{H}$ stretching vibration modes of carboxylic acid, and phenolic as well as aromatic amino functions [48]. The shift from 3,412 to $3,420 \mathrm{~cm}^{-1}$ may be due to inter- and intramolecular interactions of $\mathrm{Ag}$ with the $-\mathrm{OH}$ group [49]. The weak peaks at 2,919 and $2,840 \mathrm{~cm}^{-1}$ for aerobic and at 2,925 and $2,854 \mathrm{~cm}^{-1}$ for anaerobic conditions may be assigned to the stretching vibration of aliphatic $\mathrm{C}-\mathrm{H}$ group $[48,50]$. This shift may be attributed to the reduction of $\mathrm{Ag}^{+}$ to $\mathrm{Ag}^{0}$. The weak absorption peak at $2,360 \mathrm{~cm}^{-1}$ corresponds to the $\mathrm{O}-\mathrm{H}$ stretching vibration of phenolic hydroxyls, and the strong band at $1,645 \mathrm{~cm}^{-1}$ may be attributed to the bending vibration modes of aromatic $\mathrm{C}=\mathrm{C}$ and $\mathrm{C}=\mathrm{N}$ and to the $\mathrm{C}=\mathrm{O}$ of $(\mathrm{COOH})$ in both aerobic and anaerobic spectra [51]. The bands at 1,455 and 1,405 $\mathrm{cm}^{-1}$ were assigned to the $\mathrm{N}-\mathrm{H}$ stretch vibration present in amide linkages of the proteins, which has a role in stability/capping of Ag-NPs $[52,53]$. The band at $1,241 \mathrm{~cm}^{-1}$ corresponds to $\mathrm{C}-\mathrm{N}$ stretching of amines. The band of $1,077 \mathrm{~cm}^{-1}$ may refer to the presence of $\mathrm{C}-\mathrm{O}$ stretching of alcohols; this band intensity was higher in the anaerobic condition, indicating more quantity of alcohol extracted. Notably, the absorption bands around $500-550 \mathrm{~cm}^{-1}$ represent the stretch for Ag-NPs banding with oxygen from the hydroxyl groups. Therefore, the synthesized nanoparticles were surrounded by proteins 

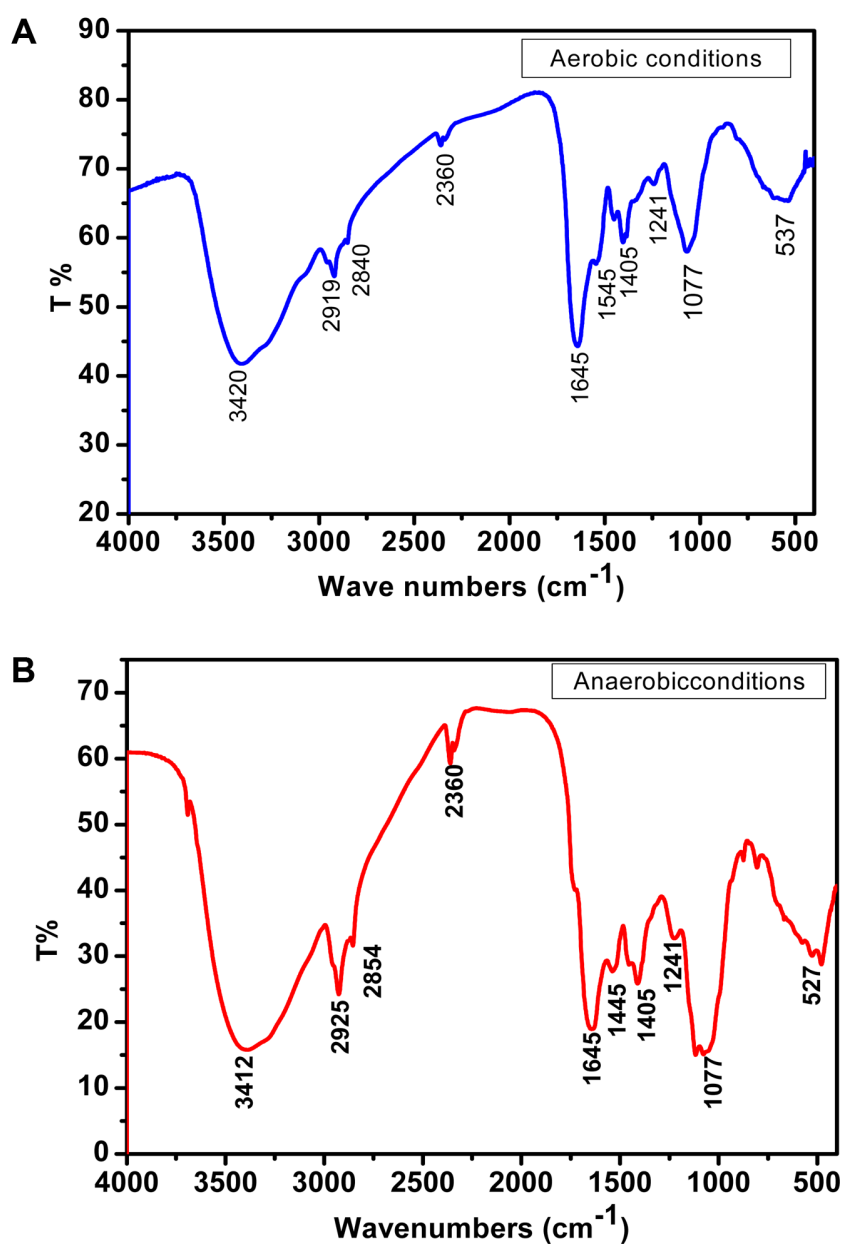

Fig. 5. FT-IR spectra of Ag/AgCl-nanoparticles produced by M. guilliermondii KX008616 under (A) aerobic and (B) anaerobic conditions.

and metabolites having functional groups [54, 55]. From the FT-IR studies, it could be confirmed that the amino acid and protein characteristic groups have an ability to bind the metal nanoparticles (i.e., capping of silver nanoparticles) to prevent agglomeration and thereby stabilizing the medium. This means that biological molecules can perform double functions to form and stabilize silver nanoparticles in the aqueous medium.

\section{Effect of Incubation Temperature on Biogenic Ag/AgCl- NP Synthesis}

Fig. 6 displays the effect of incubation temperature on the rate of production of $\mathrm{Ag} / \mathrm{AgCl}-\mathrm{NPs}$ by M. guilliermondii KX008616 under aerobic and anaerobic conditions. It is obvious that the optimum temperature for acceleration and production of biogenic nanoparticles is between $25^{\circ} \mathrm{C}$ and $30^{\circ} \mathrm{C}$. In the case of aerobic conditions, the maximum SPR peak intensity was detected at $30^{\circ} \mathrm{C}$ (Fig. 6). This revealed that by increasing the reaction temperature, a narrow peak is developed at the lower wavelength region $\left(416 \mathrm{~nm}\right.$ at $\left.30^{\circ} \mathrm{C}\right)$, which indicates the formation of smaller nanoparticles, whereas at lower temperature, the peaks observed at higher wavelength regions $\left(434 \mathrm{~nm}\right.$ at $\left.25^{\circ} \mathrm{C}\right)$ clearly indicate the increase in $\mathrm{Ag} / \mathrm{AgCl}-\mathrm{NP}$ size. These findings agree with the fact that when the temperature is increased, the reactants are consumed rapidly by the formation of silver nuclei, preventing secondary reduction on the surface of silver nuclei, leading to the formation of smaller nanoparticles. In contrast, the maximum SPR peak intensity was detected at $25^{\circ} \mathrm{C}$ in anaerobic medium (Fig. 6). By comparing the maximum SPR peak intensity in Fig. 6, it could be deduced that the production of biogenic nanoparticles in aerobic medium closed to be a fold of those of anaerobic medium, and was compatible with the XRD charts $[44,45,56]$.

\section{Effect of $\mathrm{pH}$ on Biogenic Ag/AgCl-NP Synthesis}

The medium supplemented with $\mathrm{AgNO}_{3}$ solution changed from pale brown to dark brown as the $\mathrm{pH}$ of the reaction mixture increased (Fig. 7). The intensity of the absorbance peaks was $\mathrm{pH}$ dependent. The UV-Vis spectra were recorded after the reaction at different $\mathrm{pH}$ values $(\mathrm{pH} 3-7)$ under aerobic and anaerobic conditions (Fig. 7). Different $\mathrm{pH}$ values ( $\mathrm{pH} 5,6$, and 7) resulted in significant $\mathrm{Ag} / \mathrm{AgCl}-\mathrm{NP}$ absorption bands. The maximum $\mathrm{Ag} / \mathrm{AgCl}-\mathrm{NP}$ bioproduction was at $\mathrm{pH} 7$, of which a narrow peak developed, which indicated the formation of highly dispersed bio-nanoparticles under aerobic and anaerobic conditions $[57,58]$. Biogenic synthesis of $\mathrm{Ag} / \mathrm{AgCl}-\mathrm{NPs}$ at $\mathrm{pH} 3.0$ under aerobic and anaerobic conditions showed no characteristic peak while the color of the reaction mixture was slightly changed. This change in color is related to the intracellular nanoparticle bioproduction by cell constituents as indicated by the images of the TEM (Figs. 8A and 8E). Many studies suggested that a variety of biomolecules are involved in biological nanoparticle synthesis, and such biomolecules are likely inactivated for the reducing function, like polysaccharides and proteins under extremely acidic conditions ( $\mathrm{pH} 3.0$ ), and work effectively in neutral and slightly alkaline conditions $[59,60]$. On the other hand, the noticeable difference in colors obtained over the ranges of $\mathrm{pH}$ could be ascribed to a variation in the dissociation constants (pKa) of functional groups on the biomass involved [45, 58, $61,62]$. Therefore, in the present study, $\mathrm{pH} 7$ was recorded for the biogenic synthesis of $\mathrm{Ag} / \mathrm{AgCl}-\mathrm{NPs}$. 

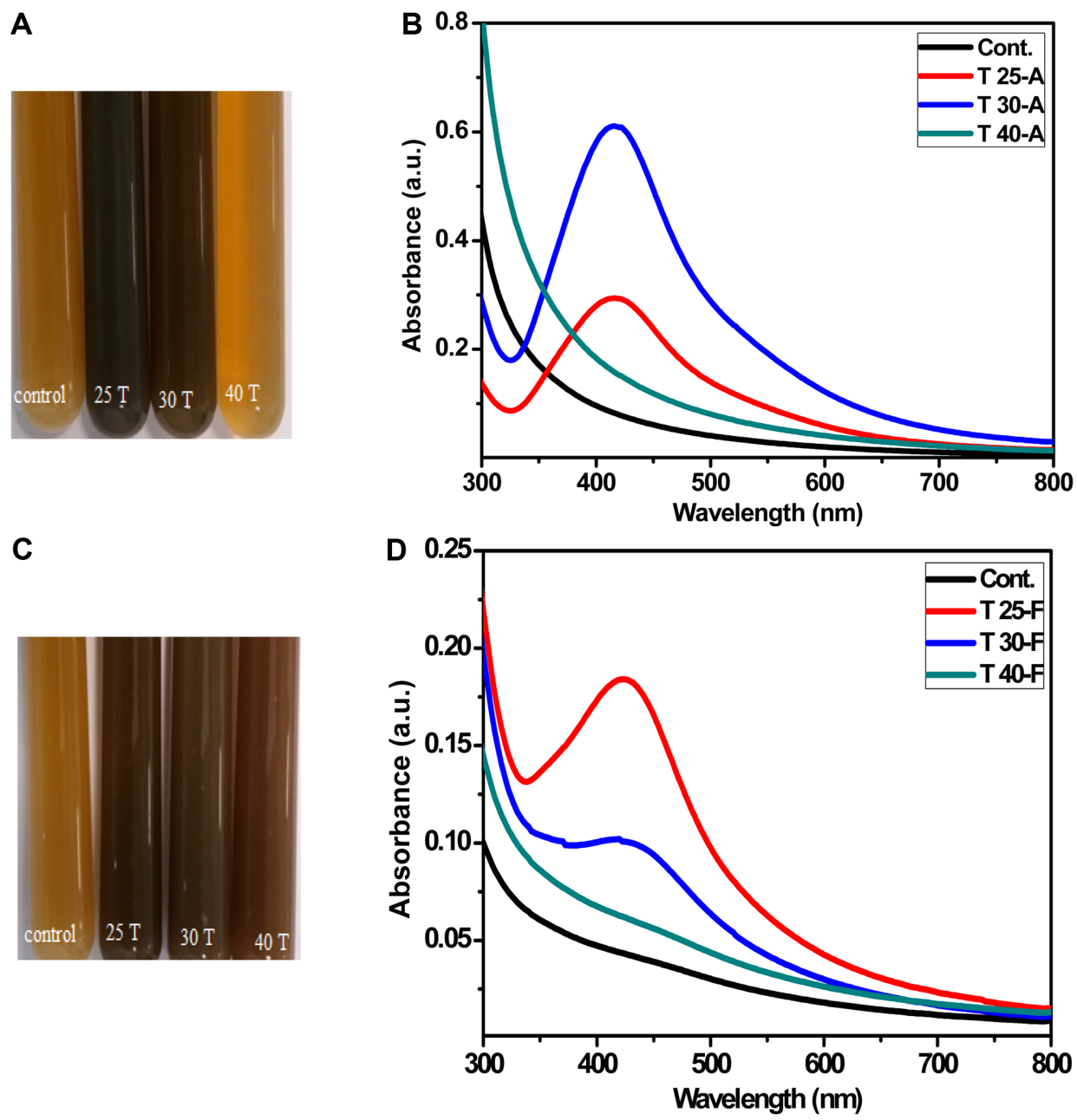

Fig. 6. Direct visualization and UV-vis absorbance spectroscopy analysis of biogenic $\mathrm{Ag} / \mathrm{AgCl}$-nanoparticles synthesized by Meyerozyma guilliermondii KX008616 under aerobic conditions at various reaction temperatures $\left(25^{\circ} \mathrm{C}, 30^{\circ} \mathrm{C}\right.$, and $\left.40^{\circ} \mathrm{C}\right)$.

(A) and (C) Color change of the reaction mixture (from left to right: control medium without $\mathrm{AgNO}_{3}$, and medium supplemented with $\mathrm{AgNO}_{3}$ at $25^{\circ} \mathrm{C}, 30^{\circ} \mathrm{C}$, and $40^{\circ} \mathrm{C}$ under (A) aerobic and (C) anaerobic conditions; (B) and (D) UV-Vis spectra under aerobic and anaerobic conditions, respectively.

The shape, size, and morphology of the biogenic $\mathrm{Ag} /$ AgCl-NPs synthesized intracellularly using M. guilliermondii KX008616 under aerobic and anaerobic conditions at various $\mathrm{pH}$ values $(3,4,5,6$, and 7$)$ were analyzed by TEM. Figs. 8A-8D of the intracellular $\mathrm{Ag} / \mathrm{AgCl}-\mathrm{NPs}$ synthesized under the aerobic condition at various $\mathrm{pH}$ values demonstrate the polydispersity nature of the nanoparticles, with clear uniform shape and size. The biogenic $\mathrm{Ag} / \mathrm{AgCl}-$ NPs were spherical and ovoid shaped with an approximate particle size of $2.5-30 \mathrm{~nm}$. Thus, M. guilliermondii KX008616 is capable of biosynthesizing $\mathrm{Ag} / \mathrm{AgCl}-\mathrm{NPs}$ small in size and more sufficient for bioapplication under the aerobic condition at pH 6 and 7. Moreover, the biogenic $\mathrm{Ag} / \mathrm{AgCl}-$ NPs synthesized under the anaerobic condition at various
$\mathrm{pH}$ values were examined (Figs. $8 \mathrm{E}-8 \mathrm{H}$ ). It was clear that the biogenic nanoparticles with a larger size were in the range of 5-80 $\mathrm{nm}$ and displayed polydispersity. There were dissimilarities in the shapes of the biogenic nanoparticles based on the images of the TEM, of which spherical, triangular, hexagonal, and polyhedral nanoparticles were found under anaerobic condition. The nanoparticle formation of different shapes and sizes could be due to the presence of more than one reducing agent in yeast cells.

\section{Ultrathin Section of Yeast Cells during the Formation of Biogenic Nanoparticles}

TEM study of yeast cells revealed that the biosynthesis of $\mathrm{Ag} / \mathrm{AgCl}-\mathrm{NPs}$ was occurring inside the cell. M. guilliermondii 

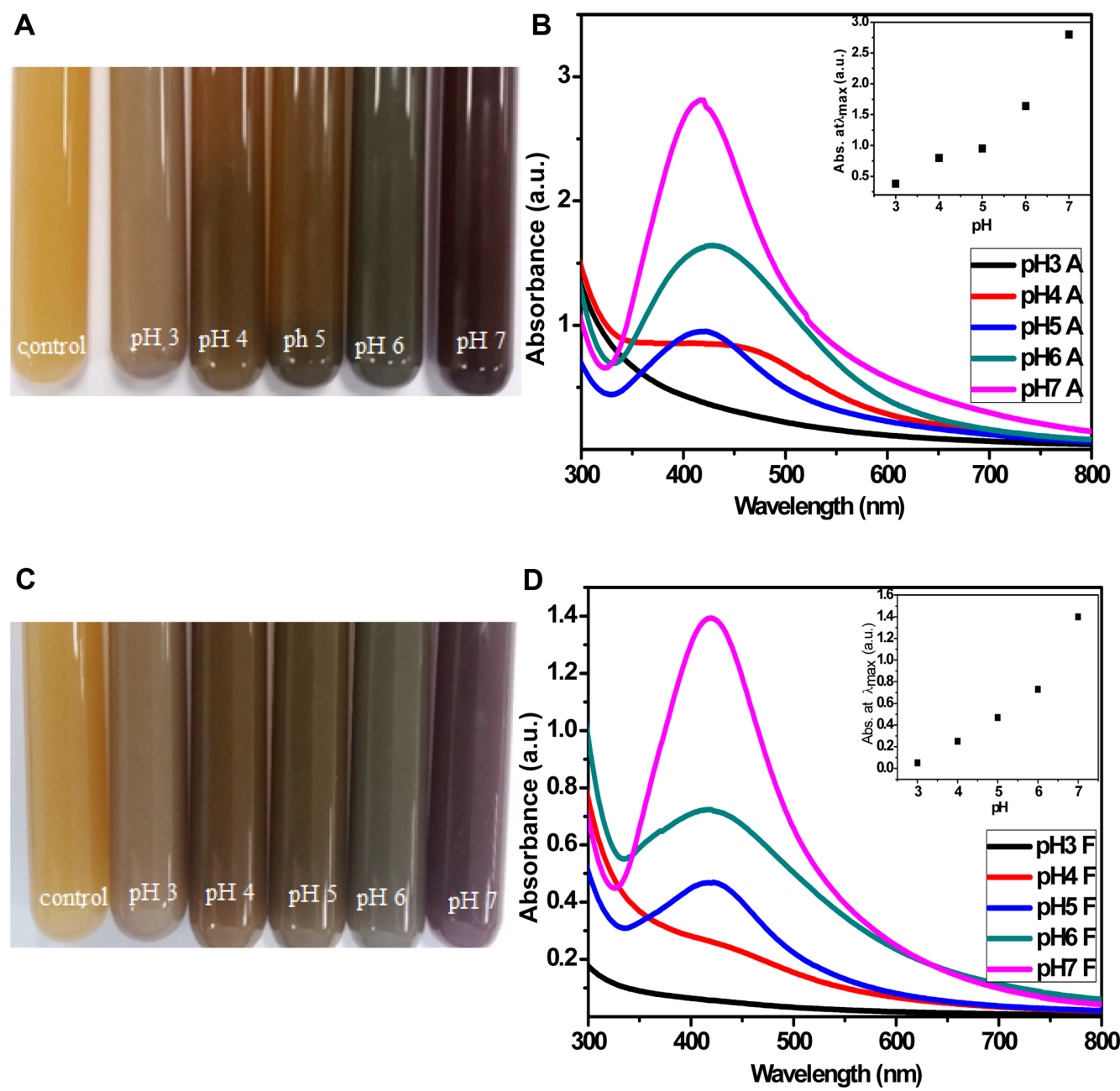

Fig. 7. Direct visualization and UV-Vis absorbance spectroscopy analysis of biogenic $\mathrm{Ag} / \mathrm{AgCl}$-nanoparticles synthesized by Meyerozyma guilliermondii KX008616 under aerobic conditions at $25^{\circ} \mathrm{C}$ and various $\mathrm{pH}$ values $(3,4,5,6$, and 7$)$.

(A) and (C) Color change of the reaction mixture (from left to right: control medium without $\mathrm{AgNO}_{3}$, and medium supplemented with $\mathrm{AgNO}$ at $\mathrm{pH} 3,4,6$, and 7 under (A) aerobic and (C) anaerobic conditions; (B) and (D) UV-Vis spectra under aerobic and anaerobic conditions, respectively.

KX008616 grown under aerobic and anaerobic conditions and exposed to an aqueous solution of the silver nitrate resulted in a biogenic intracellular activity of the $\mathrm{Ag} / \mathrm{AgCl}$ NPs. Fig. 9 shows that at $\mathrm{pH} 3$, yeast cells grown aerobically formed the biogenic nanoparticles inside the cells; in the cytoplasm as clusters. These clusters are known as nanoaggregates [28]. The reduction, in this case, was much slower and the production yield of nanoparticles was little. At pH 5 and 7, intracellular Ag/AgCl-NPs were arranged as nanoaggregates along the cell wall. Figs. 9B9D show nanoaggregates mostly associated with inner and outer regions of the cell wall with uniform shapes and varied sizes. Additionally, yeast cells were grown aerobically at pH 5 and 7, and besides accumulating silver nanoparticle types inside the cell, biogenic nanoparticles were secreted outside the cell [63].

In order to investigate the variation in shapes and sizes of intracellular biogenic $\mathrm{Ag} / \mathrm{AgCl}-\mathrm{NPs}$ under the anaerobic condition at various $\mathrm{pH}$ values, we examined yeast cells by ultrathin sections with TEM (Fig. 10). At pH 3, yeast cells slightly formed intracellular nanoparticles inside the cells, of which a small population was formed in the cytoplasm away from the cell wall (Figs. 10A and 10B). It was clear that yeast cells grown anaerobically at $\mathrm{pH} 5$ synthesized nanoaggregates in the cytoplasm and in the cell wall (Figs. 10C and 10D). At pH 7, Ag/AgCl-NPs were confirmed in the outer and inner regions of the cell wall (Figs. 10E-10F) and no clear association with the cytoplasm or intracellular 

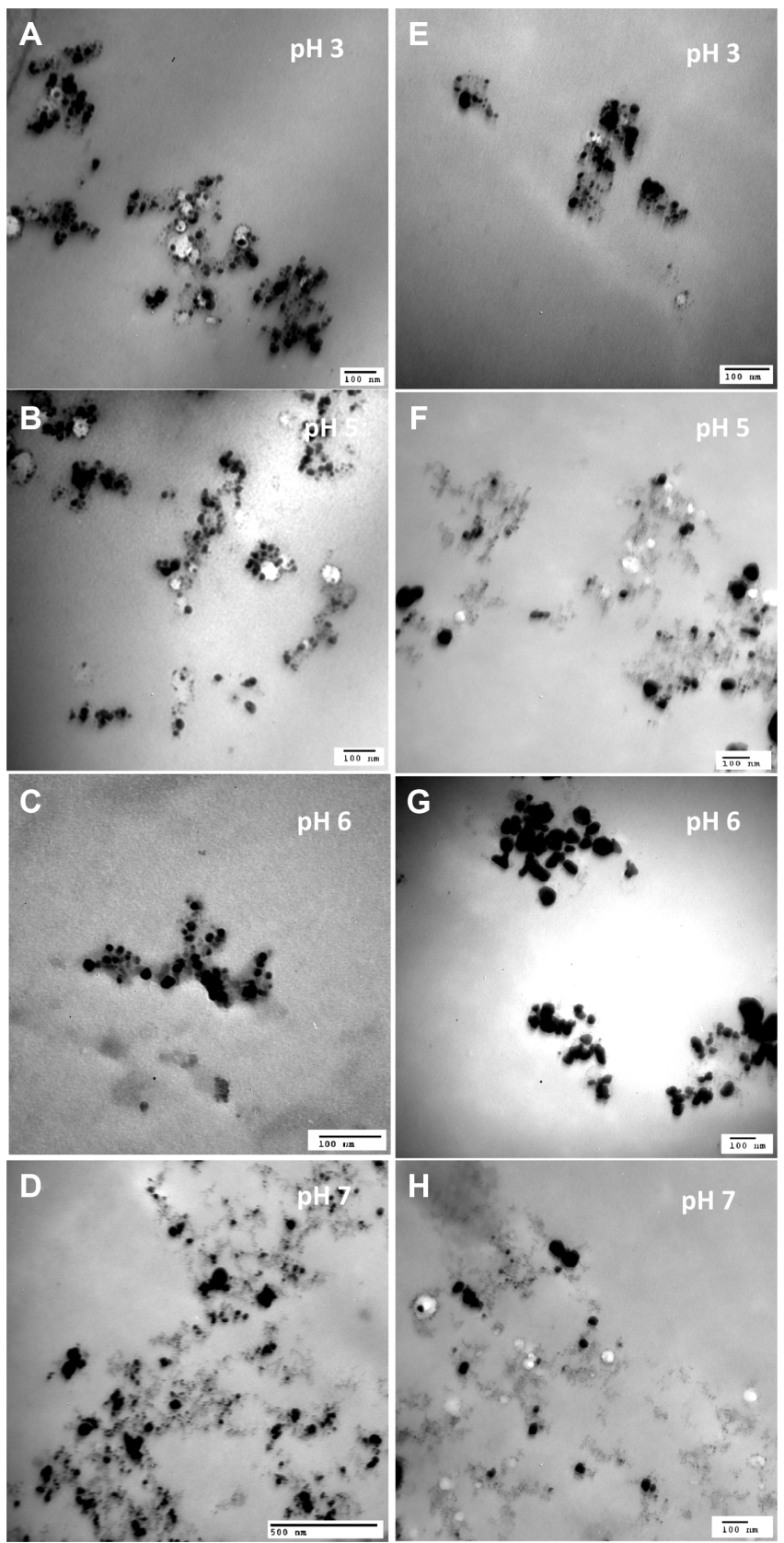

Fig. 8. Transmission electron micrographs of biogenic $\mathrm{Ag} / \mathrm{AgCl}-$ nanoparticles synthesized intracellularly using Meyerozyma guilliermondii KX008616 under (A-D) aerobic and $(\mathbf{C}-\mathbf{H})$ anaerobic conditions at $25^{\circ} \mathrm{C}$ and various $\mathrm{pH}$ values.

structures was found. The variation in the shape and size are due to the interaction of different intracellular structures with different crystallographic faces of the Ag/ AgClNPs. It was confirmed that yeasts containing nitrate reductase enzyme involved silver nanoparticle production because
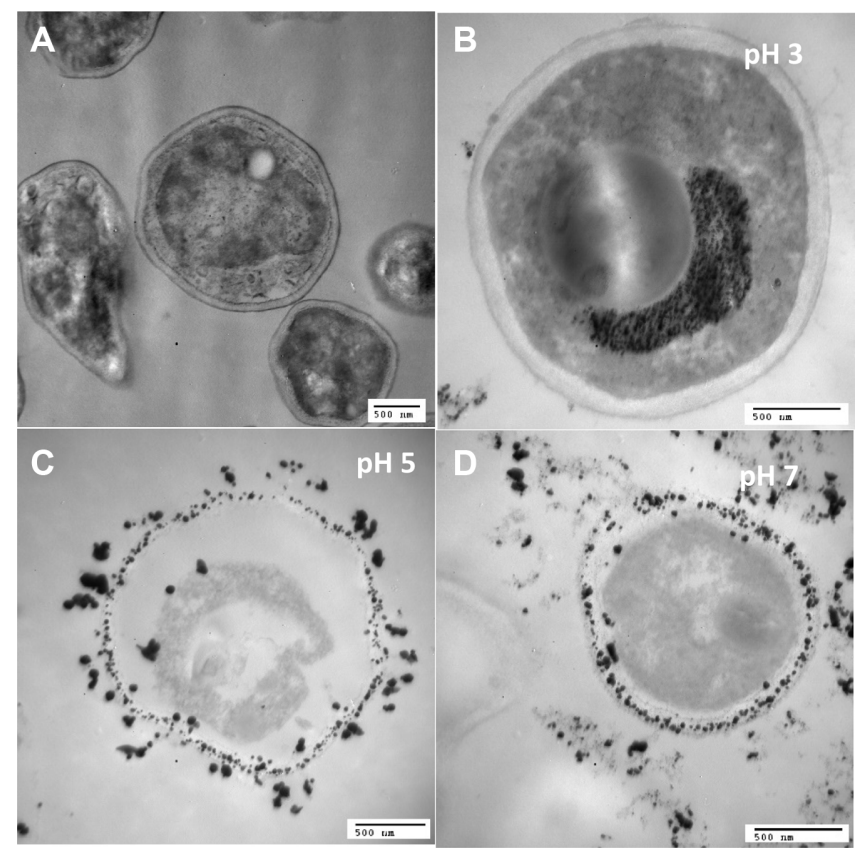

Fig. 9. Transmission electron micrographs of yeast cells (Meyerozyma guilliermondii KX008616) during the formation of biogenic $\mathrm{Ag} / \mathrm{AgCl}$-nanoparticles under aerobic condition at $25^{\circ} \mathrm{C}$ and various $\mathrm{pH}$ values.

(A) Control yeast cells. (B-D) Yeast cells exposed to $\mathrm{AgNO}_{3}$ at $\mathrm{pH} 3$, 5 , and 7 .

this enzyme seems to be involved in silver nanoparticle synthesis [64, 65].

\section{Bioethanol Production by Meyerozyma guilliermondii}

The production of ethanol was assessed during the fermentation period and the results confirmed that after $36 \mathrm{~h}$, the maximum production of ethanol was achieved by M. guilliermondii KX008616 in the fermentation medium without $\mathrm{AgNO}_{3}$. However, a low concentration of $\mathrm{AgNO}_{3}$ ( $2 \mathrm{mM}$ ) enhanced the productivity of ethanol by this yeast, which reached $4.0 \mathrm{~g} / 1$ after $48 \mathrm{~h}$ of incubation. In contrast, the higher concentrations of $\mathrm{AgNO}_{3}(4-6 \mathrm{mM})$ had a negative impact on the production of ethanol by the same yeast. The highest concentration of $\mathrm{AgNO}_{3}$ creased the production of ethanol after $12 \mathrm{~h}$, which indicated the toxic effect of this dose of metal on yeast cells. The results confirm that the yeast M. guilliermondii KX008616 is a Agresistant strain that could resist the concentration of the metal to $6 \mathrm{mM}$. However, higher concentrations could be toxic to the cells of this yeast. In accordance with our findings, Kowshik et al. [66] reported that the yeast strain MKY3 synthesized silver nanoparticles extracellularly 

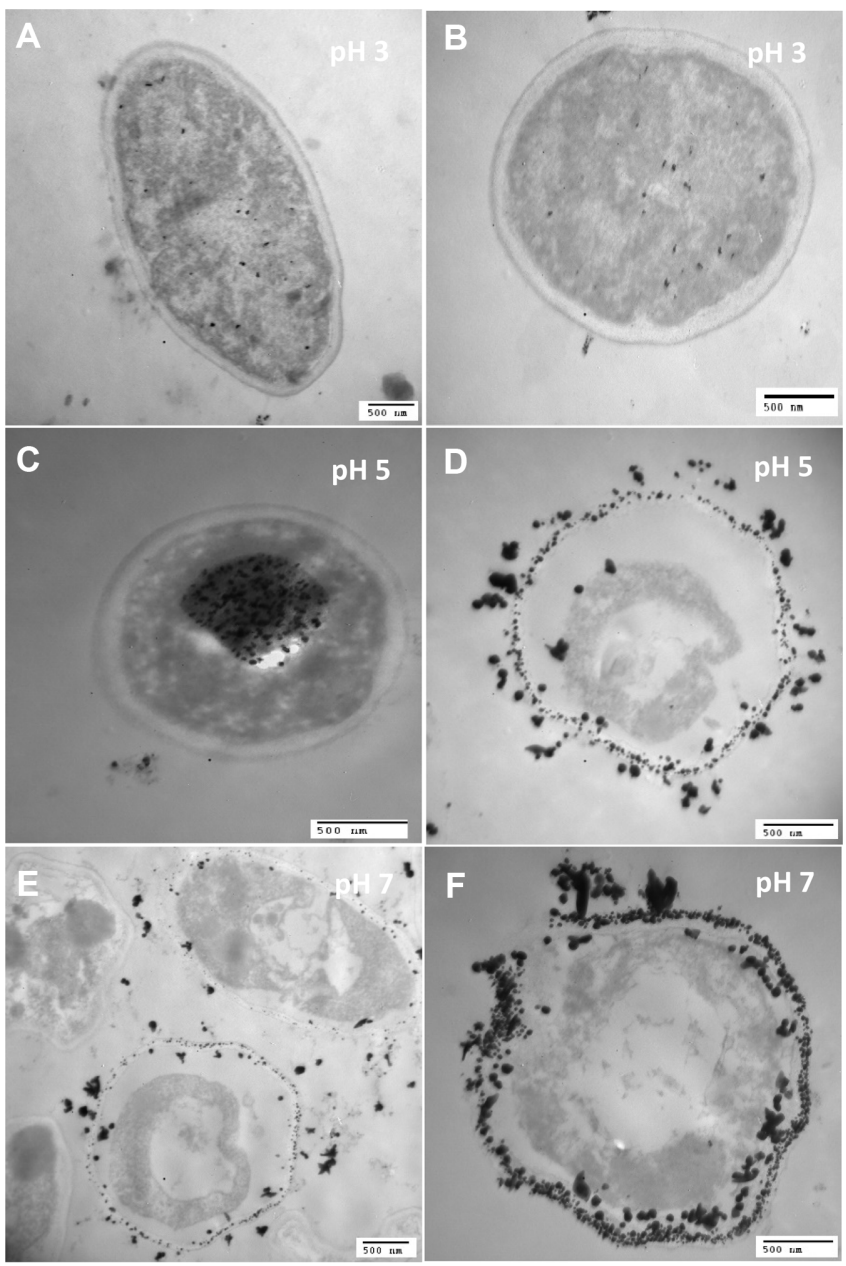

Fig. 10. Transmission electron micrographs of yeast cells (Meyerozyma guilliermondii KX008616) during the formation of biogenic $\mathrm{Ag} / \mathrm{AgCl}$-nanoparticles under anaerobic condition at $25^{\circ} \mathrm{C}$ and various $\mathrm{pH}$ values.

(A-F) Yeast cells exposed to $\mathrm{AgNO}_{3}$ at $\mathrm{pH} 3,5$, and 7.

during its growth in a medium supplemented with $1 \mathrm{mM}$ silver, and this strain denoted a silver-tolerant yeast. There is no available information about the effect of silver metal on the ethanol production by fermentative yeasts. However, we could assume that the production of ethanol decreased with increase in silver concentration up to $6 \mathrm{mM}$ and was completely inhibited at $8 \mathrm{mM}$ because of the toxic effect of the metal ions on vegetative growth of the cell that could interfere with or suppress the enzyme reactions.

Our results proved for the first time the intracellular synthesis of Ag/AgCl-NPs by M. guilliermondii KX008616 under both aerobic and anaerobic conditions. Results showed the variation in size and shape among the Ag/ $\mathrm{AgCl}-\mathrm{NPs}$ that were synthesized either aerobically or

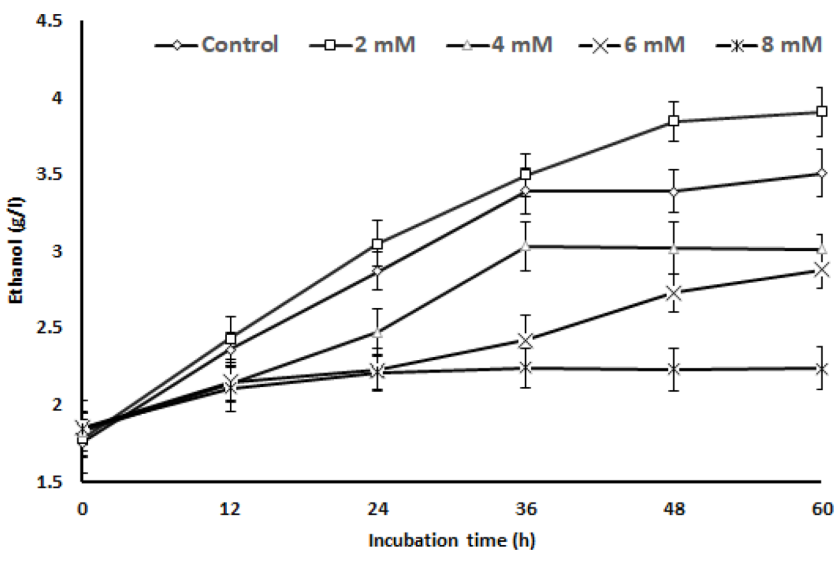

Fig. 11. Production of ethanol by Meyerozyma guilliermondii $\mathrm{KX} 008616$ in the presence of different concentration of $\mathrm{AgNO}_{3}$ (2-8 $\mathrm{mM})$ under anaerobic conditions.

Bars represent the standard error.

anaerobically. In aerobic condition, the $\mathrm{Ag} / \mathrm{AgCl}-\mathrm{NPs}$ were homogeneous and spherical in shape with an approximate particle size of $2.5-30 \mathrm{~nm}$. However, under anaerobic conditions, the biogenic nanoparticles were larger in size (5-80 nm) and displayed polydispersity. Our results assume that intracellular, extracellular, or surface production of the nanoparticle by this yeast could be $\mathrm{pH}$-dependent. However, more indepth research is needed to define the exact mechanism that could be involved in this procedure. In addition, production of ethanol by this yeast strain in the presence of a high concentration of silver $(6 \mathrm{mM})$ confirms its resistance to the metal and could be denoted as a silvertolerant yeast. Furthermore, the ability of this yeast to produce $\mathrm{Ag} / \mathrm{AgCl}-\mathrm{NPs}$ from the culture medium could encourage use of the biomass of yeasts from industrial or fermentation purposes for the production of $\mathrm{Ag} / \mathrm{AgCl}-\mathrm{NPs}$ as associated by-products to maximize benefit and to reduce the production cost.

\section{Acknowledgments}

The authors extend their appreciation to the Deanship of Scientific Research at King Khalid University for funding this work through General Research Project under the grant number G.R.P-168-38.

\section{Conflict of Interest}

The authors have no financial conflicts of interest to declare. 


\section{References}

1. Birla SS, Gaikwad SC, Gade AK, Rai MK. 2013. Rapid synthesis of silver nanoparticles from Fusarium oxysporum by optimizing physicocultural conditions. Scientific World Journal 2013: 796018.

2. Husseiny SM, Salah TA, Anter HA. 2015. Biosynthesis of size controlled silver nanoparticles by Fusarium oxysporum, their antibacterial and antitumor activities. Beni-Suef Univ. J. Basic Appl. Sci. 4: 225-231.

3. Mahendra R, Nelson D. 2011. Metal Nanoparticles in Microbiology. Springer, Heidelberg, Germany.

4. Mekkawy AI, El-Mokhtar MA, Nafady NA, Yousef N, Hamad MA, El-Shanawany SM, et al. 2017. In vitro and in vivo evaluation of biologically synthesized silver nanoparticles for topical applications: effect of surface coating and loading into hydrogels. Int. J. Nanomed. 12: 759-777.

5. Nanda A, Majeed S. 2014. Enhanced antibacterial efficacy of biosynthesized AgNPs from Penicillium glabrum (MTCC1985) pooled with different drugs. Int. J. Pharm. Tech. Res. 6: 217-223.

6. Dasgupta N, Ranjan S, Rajendran B, Manickam V, Ramalingam C, Avadhani GS, et al. 2016. Thermal coreduction approach to vary size of silver nanoparticle: its microbial and cellular toxicology. Environ. Sci. Pollut. Res. 23: 4149-4163.

7. Naseem T, Farrukh MA. 2015. Antibacterial activity of green synthesis of iron nanoparticles using Lawsonia inermis and Gardenia jasminoides leaves extract. J. Chem. 2015: 912342.

8. Netala VR, Kotakadi VS, Bobbu P, Gaddam SA, Tartte V. 2016. Endophytic fungal isolate mediated biosynthesis of silver nanoparticles and their free radical scavenging activity and anti-microbial studies. 3 Biotech 6: 1-9.

9. Gaikwad S, Ingle A, Gade A, Rai M, Falanga A, Incoronato N, et al. 2013. Antiviral activity of mycosynthesized silver nanoparticles against herpes simplex virus and human parainfluenza virus type 3. Int. J. Nanomed. 8: 4303-4314.

10. Daenen LG, Houthuijzen JM, Cirkel GA, Roodhart JML, Shaked Y, Voest EE. 2014. Treatment induced host-mediated mechanisms reducing the efficacy of antitumor therapies. Oncogene 33: 1341-1347.

11. Kim HS, Lee CR, Im JH, Lee KB, Moehl T, Marchioro A, et al. 2012. Lead iodide perovskite sensitized all-solid-state submicron thin film mesoscopic solar cell with efficiency exceeding 9\%. Sci. Rep. 2: 519.

12. Said DE, Elsamad LM, Gohar YM. 2012. Validity of silver, chitosan, and curcumin nanoparticles as anti-Giardia agents. Parasitol. Res. 111: 545-554.

13. Muthukumaran, U, Govindarajan M, Rajeswary M, Hoti SL. 2015. Synthesis and characterization of silver nanoparticles using Gmelina asiatica leaf extract against filariasis, dengue, and malaria vector mosquitoes. Parasitol. Res. 114: 1817-1827.

14. Garg S, Chandra A. 2012. Biosynthesis and anthelmintic activity of silver nanoparticles using aqueous extract of
Saraca indica leaves. Int. J. Ther. Appl. 7: 9-12.

15. Marimuthu S, Rahuman AA, Jayaseelan C, Kirthi AV, Santhoshkumar T, Velayutham K, et al. 2013. Acaricidal activity of synthesized titanium dioxide nanoparticles using Calotropis gigantea against Rhipicephalus microplus and Haemaphysalis bispinosa. Asian Pac. J. Trop. Med. 66: 82-688.

16. Shelar GB, Chavan AM. 2014. Fungus-mediated biosynthesis of silver nanoparticles and its antibacterial activity. Arch. Appl. Sci. Res. 6: 111-114.

17. Patel V, Berthold D, Puranik P, Gantar M. 2015. Screening of cyanobacteria and microalgae for their ability to synthesize silver nanoparticles with antibacterial activity. Biotechnol. Rep. 5: 112-119.

18. Lee H, Purdon AM, Chu V, Westervelt RM. 2004. Controlled assembly of magnetic nanoparticles from magnetotactic bacteria using microelectromagnets arrays. Nano Lett. 4: 995998.

19. Lengke MF, Fleet ME, Southam G. 2007. Biosynthesis of silver nanoparticles by filamentous cyanobacteria from a silver(I) nitrate complex. Langmuir 23: 2694-2699.

20. Ahmad A, Senapati S, Khan MI, Kumar R, Ramani R, Srinivas V, et al. 2003. Intracellular synthesis of gold nanoparticles by a novel alkalotolerant actinomycete, Rhodococcus species. Nanotechnology 14: 824.

21. Vigneshwaran N, Kathe AA, Varadarajan PV, Nachane RP, Balasubramanya RH. 2007. Functional finishing of cotton fabrics using silver nanoparticles. J. Nanosci. Nanotechnol. 7: 1893-1897.

22. Ingle A, Gade A, Pierrat S, Sonnichsen C, Rai M. 2008. Mycosynthesis of silver nanoparticles using the fungus Fusarium acuminatum and its activity against some human pathogenic bacteria. Curr. Nanosci. 4: 141-144.

23. Birla SS, Tiwari VV, Gade AK, Ingle AP, Yadav AP, Rai, MK. 2009. Fabrication of silver nanoparticles by Phoma glomerata and its combined effect against Escherichia coli, Pseudomonas aeruginosa and Staphylococcus aureus. Lett. Appl. Microbiol. 48: 173-179.

24. Agnihotri M, Joshi S, Kumar AR, Zinjarde S, Kulkarni S. 2009. Biosynthesis of gold nanoparticles by the tropical marine yeast Yarrowia lipolytica NCIM 3589. Mater. Lett. 63: 1231-1234.

25. Apte M, Sambre D, Gaikawad S, Joshi S, Bankar A, Kumar AR, et al. 2013. Psychrotrophic yeast Yarrowia lipolytica NCYC 789 mediates the synthesis of antimicrobial silver nanoparticles via cell-associated melanin. AMB Express 3: 32.

26. Mourato A, Gadanho M, Lino AR, Tenreiro R. 2011. Biosynthesis of crystalline silver and gold nanoparticles by extremophilic yeasts. Bioinorg. Chem. Appl. 2011: 546074.

27. Fernández JG, Fernández-Baldo MA, Berni E, Camí G, Durán N, Raba J, et al. 2016. Production of silver nanoparticles using yeasts and evaluation of their antifungal activity against phytopathogenic fungi. Process Biochem. 51: 1306-1313.

28. Eugenio M, Müller N, Frasés S, Almeida-Paes R, Lima LMT, 
Lemgruber L, et al. 2016. Yeast-derived biosynthesis of silver/silver chloride nanoparticles and their antiproliferative activity against bacteria. RSC Adv. 6: 9893-9904.

29. Krumov N, Perner-Nochta I, Oder S, Gotcheva V, Angelov A, Posten C. 2009. Production of inorganic nanoparticles by microorganisms. Chem. Eng. Technol. 32: 1026-1035.

30. Kurtzman CP, Fell JW. 1998. Definition, classification and nomenclature of the yeasts, pp 3-5. In Kurtzman CP, Fell JW (eds.), The Yeasts, A Taxonomic Study, 4th Ed. Elsevier Science BV, Amsterdam, The Netherlands.

31. Hesham A, Wang Z, Zhang Y, Zhang J, Lv W, Yang M. 2006. Isolation and identification of a yeast strain capable of degrading four and five ring aromatic hydrocarbons. Ann. Microbiol. 56: 109-112.

32. Kurtzman CP, Robnett CJ. 1998. Identification and phylogeny of ascomycetous yeasts from analysis of nuclear large subunit (26S) ribosomal DNA partial sequences. Antonie Van Leeuwenhoek 73: 331-371.

33. Hashem M, Hesham AE-L, Alrumman SA, Alamri SA, Moustafa MFM. 2014. Indigenous yeasts of the rotten date fruits and their potentiality in bioethanol and single-cell protein production. Int. J. Agric. Biol. 16: 752-758.

34. Moghaddam AB, Namvar F, Moniri M, Tahir PM, Azizi S, Mohamad R. 2015. Nanoparticles biosynthesized by fungi and yeast: a review of their preparation, properties, and medical applications. Molecules 20: 16540-16565.

35. Jha AK, Prasad K, Kulkarni AR. 2008. Yeast mediated synthesis of silver nanoparticles. Int. J. Nanosci. Nanotechnol. 4: $17-22$.

36. Durán N, Marcato PD, Alves OL, Souza GI, Esposito E. 2005. Mechanistic aspects of biosynthesis of silver nanoparticles by several Fusarium oxysporum strains. J. Nanobiotechnology 3: 8 .

37. Reese RN, Winge DR. 1988. Sulfide stabilization of the cadmiumgamma-glutamyl peptide complex of Schizosaccharomyces pombe. J. Biol. Chem. 263: 12832-12835.

38. Dameron CT, Reese RN, Mehra RK, Kortan AR, Carroll PJ, Steigerwald ML, et al. 1989. Biosynthesis of cadmium sulphide quantum semiconductor crystallites. Nature 338: 596-597.

39. Gole A, Dash C, Ramakrishnan V, Sainkar SR, Mandale AB, Rao M, et al. 2001. Pepsin-gold colloid conjugates: preparation, characterization, and enzymatic activity. Langmuir 17: 1674-1679.

40. Bhainsa KC, D'Souza SF. 2006. Extracellular biosynthesis of silver nanoparticles using the fungus Aspergillus fumigatus. Colloids Surf. B Biointerfaces 47: 160-164.

41. Virkutyte J, Varma RS. 2011. Green synthesis of metal nanoparticles: biodegradable polymers and enzymes in stabilization and surface functionalization. Chem. Sci. 2: 837-846.

42. Kou J, Varma RS. 2012. Beet juice-induced green fabrication of plasmonic $\mathrm{AgCl} / \mathrm{Ag}$ nanoparticles. ChemSusChem. 5: 2435-2441.

43. Azizi S, Namvar F, Mahdavi M, Ahmad MB, Mohamad R.
2013. Biosynthesis of silver nanoparticles using brown marine macroalga, Sargassum muticum aqueous extract. Materials (Basel) 6: 5942-5950.

44. Abdel-Hafez SII, Nafady NA, Abdel-Rahim IR, Shaltout AM, Darós J-A, Mohamed AM. 2016. Assessment of protein silver nanoparticles toxicity against pathogenic Alternaria solani. 3 Biotech 6: 199-211.

45. Abdel-Hafez SII, Nafady NA, Abdel-Rahim IR, Shaltout AM, Mohamed AM. 2016. Biogenesis and optimisation of silver nanoparticles by the endophytic fungus Cladosporium sphaerospermum. Int. J. Nano Chem. 2: 11-19.

46. Durán N, Cuevas R, Cordi L, Rubilar O, Diez MC. 2014. Biogenic silver nanoparticles associated with silver chloride nanoparticles (Ag@AgCl) produced by laccase from Trametes versicolor. Springerplus 3: 645.

47. Wang P, Huang B, Lou Z, Zhang X, Qin X, Dai Y, et al. 2010. Synthesis of highly efficient $\mathrm{Ag} / \mathrm{AgCl}$ plasmonic photocatalysts with various structures. Chem. Eur. J. 16: 538-544.

48. Centeno SA, Shamir J. 2008. Surface enhanced Raman scattering (SERS) and FTIR characterization of the sepia melanin pigment used in works of art. J. Mol. Struct. 873: 149-159.

49. Nnemeka I, Godwin E-U, Olakunle F, Olushola O, Moses O, Chidozie OP, et al. 2016. Microwave enhanced synthesis of silver nanoparticles using orange peel extracts from Nigeria. Chem. Biomol. Eng. 1: 5-11.

50. Tarangini K, Mishra S. 2013. Production, characterization and analysis of melanin from isolated marine Pseudomonas sp. using vegetable waste. Res. J. Engin. Sci. 2: 40-46.

51. Apte M, Girme G, Bankar A, Ravi KA, Zinjarde S. 2013. 3,4-dihydroxy-L-phenylalanine-derived melanin from Yarrowia lipolytica mediates the synthesis of silver and gold nanostructures. J. Nanobiotechnology 11: 1-9

52. Niraimathi KL, Sudha V, Lavanya R, Brindha P. 2013. Biosynthesis of silver nanoparticles using Alternanthera sessilis (Linn.) extract and their antimicrobial, antioxidant activities. Colloids Surf. B Biointerfaces 102: 288-291.

53. Prakash P, Gnanaprakasam P, Emmanuel R, Arokiyaraj S, Saravanan M. 2013. Green synthesis of silver nanoparticles from leaf extract of Mimusops elengi, Linn. for enhanced antibacterial activity against multi drug resistant clinical isolates. Colloids Surf. B Biointerfaces 108: 255-259.

54. Shameli K, Ahmad MB, Zamanian A, Sangpour P, Shabanzadeh P, Abdollahi Y, et al. 2012. Green biosynthesis of silver nanoparticles using Curcuma longa tuber powder. Int. J. Nanomed. 7: 5603-5610.

55. Kora AJ, Beedu SR, Jayaraman A. 2012. Size-controlled green synthesis of silver nanoparticles mediated by gum ghatti (Anogeissus latifolia) and its biological activity. Org. Med. Chem. Lett. 2: 17-27.

56. Pimprikar PS. 2009. Influence of biomass and gold salt concentration on nanoparticle synthesis by the tropical 
marine yeast Yarrowia lipolytica NCIM 3589. Colloids Surf. B Biointerfaces 7: 309-316.

57. Cruz D, Fale PL, Mourato A, Vaz PD, Serralheiro ML, Lino AR. 2010. Preparation and physicochemical characterization of Ag nanoparticles biosynthesized by Lippia citriodora (Lemon Verbena). Colloids Surf. B Biointerfaces 81: 67-73.

58. Baghizadeh A, Ranjbar S, Gupta VK, Asif M, Pourseyedi S, Karimi MJ, et al. 2015. Green synthesis of silver nanoparticles using seed extract of Calendula officinalis in liquid phase. J. Mol. Liq. 207: 159-163.

59. Sathiyanarayanan G, Kiran GS, Selvin J. 2013. Synthesis of silver nanoparticles by polysaccharide bioflocculant produced from marine Bacillus subtilis MSBN17. Colloids Surf. B Biointerfaces 102: 13-20.

60. Suman TY, Rajasree SRR, Kanchana A, Elizabeth SB. 2013. Biosynthesis, characterization and cytotoxic effect of plant mediated silver nanoparticles using Morinda citrifolia root extract. Colloids Surf. B Biointerfaces 106: 74-78.

61. Mandal S, Phadtare S, Sastry M. 2005. Interfacing biology with nanoparticles. Curr. Appl. Phys. 5: 118-127.

62. Roopan SM, Madhumitha G, Rahuman AA, Kamaraj C, Bharathi A, Surendra TV. 2013. Low-cost and eco-friendly phyto-synthesis of silver nanoparticles using Coos nucifera Coir extract and its larvicidal activity. Ind. Crops Prod. 43: 631-635.

63. Singh R, Shedbalkar UU, Wadhwani SA, Chopade BA. 2015. Bacteriagenic silver nanoparticles: synthesis, mechanism, and applications. Appl. Microbiol. Biotechnol. 99: 4579-4593.

64. Durán N, Marcato PD, Alves OL, De Souza GIH, Esposito E. 2005. Mechanistic aspects of biosynthesis of silver nanoparticles by several Fusarium oxysporum strains. J. Nanobiotechnology 3: $1-8$.

65. Saifuddin N, Wong CW, Nur Yasumira AA. 2009. Rapid biosynthesis of silver nanoparticles using culture supernatant of bacteria with microwave irradiation. E-J. Chem. 6: 61-70.

66. Kowshik M, Ashtaputre S, Kulkani SK, Parknikar KMM. 2003. Extracellular synthesis of silver nanoparticles by a silver-tolerant yeast strain MKY3. Nanotechnology 14: 95-100. 